Fecha de recepción: julio 2020

Fecha de aprobación: octubre 2020

Fecha publicación: enero 2021

\section{La necesidad de actualizar y modernizar la enseñanza de la Historia: hacia un sentido de vida y pertenencia en los niños}

Linda Sacal Halabe ${ }^{(1)}$

Resumen: Las nuevas generaciones requieren y demandan nuevas maneras de aprendizaje. Es necesario replantear y actualizar los conocimientos que se les imparten. La enseñanza de la Historia en las aulas debe reformularse. Las nuevas tecnologías aplicadas a la teoría de Framing, a un proceso de extrañamiento, a recursos estéticos creativos y a la recepción literaria en su interacción con el medio exterior, a través de la narrativa histórica infantil son una alternativa para abrir un gran abanico de posibilidades y fomentar un espacio de reflexión, comprensión e identificación con el pasado.

Palabras clave: Narrativa histórica - Narrativa infantil - Historia - Enseñanza - Framing.

[Resúmenes en inglés y portugués en las páginas 71-72]

(1) Doctora en Letras Modernas por la Universidad Iberoamericana de México, con el tema "Narrativa histórica infantil". Maestra en Historia por la misma institución. Licenciada en Historia por la Escuela Nacional de Antropología e Historia donde impartió la materia "Familia e infancia durante la Colonia. Siglo XVIII". Participó en el proyecto de reestructuración del Museo Nacional de Intervenciones del 2005 al 2007.

...el pasado reescribe, en las novelas, la historia del porvenir. (Tomás Eloy Martínez, 1996, p. 131).

Una de las principales inquietudes de toda sociedad es conservar toda aquella experiencia que va enriqueciendo culturalmente a su pueblo, y ello se ha logrado gracias a la elaboración de medidas articuladas como la memoria escrita, que además de aportar conocimiento permite identificarse con su propia historia y comprender el presente.

Sioli Cristancho Albornoz considera que la Historia oficial se ha preocupado por explorar y difundir los actos de los héroes de nuestra nación, que no dejan de ser importantes, pero incluye sólo a un número muy reducido de la población, mientras que la vida del pueblo ha sido censurada y silenciada por ser considerada sin importancia. Elsa González y Gu- 
mersindo Vera lo exponen así: "Se nos ha enseñado la historia como una suma de hechos lineales vividos por 'una sociedad' -sin cara y sin rostro- en un tiempo pasado, y cuya tendencia nos ha determinado en lo que hoy somos y seremos mañana, sin opción de ser algo diferente" (González y Vera, 2007, p. 37).

Los conocimientos históricos adquiridos en las aulas exponen, en la mayoría de los casos, la versión oficial que desea comunicar el aparato estatal por medio de sus libros, con la intención de fundamentar su legitimidad a través de un pasado común y de esa manera crear una unidad social que les aporte una identidad, ideología, orientación y tendencia nacional que justifique las acciones de los gobernantes, para manipular “... la tradición histórica instalada en el imaginario del país” (Eloy Martínez, 1996, p. 121). La historia enseñada no explica las diferentes interpretaciones que hay sobre cada tema, por lo que se pretende que los estudiantes consideren a la Historia como: “... algo cerrado, único y verdadero" (Carretero, Castorina, Sarti, Van Alphen y Barreiro, 2013, p. 16). Es un espacio de fechas y datos donde a los protagonistas de nuestra nación se les ha dotado de rasgos determinados y han sido incorporados a toda una serie de mitos fundacionales para poder crear una identidad nacional y reivindicar el espíritu nacional, pues al ser el pasado inexistente en el presente requiere de registros para validarse, debido a que "Todo lo no tangible reta la conciencia de su existencia” (Cristancho, 2004, p. 158). Sin embargo, es importante hacer notar que el manejo de nuestro pasado debe hacerse con gran cuidado porque: “... manipular y falsificar la historia de un pueblo es uno de los primeros pasos para destruir su conciencia histórica y tratar de cercenar su libertad" (Mata, 1995, p. 40).

Sioli Cristancho da un ejemplo al respecto:

$\mathrm{Al}$ descubrir la existencia de un espacio que no encajaba en lo ya conocido y al aceptar que estas tierras eran diferentes, Colón estaba dando cabida a que ingresara en la mentalidad medieval una ruptura y a su vez se iniciara la construcción de una realidad, pero esto último no fue logrado. Se iniciaba esta nueva realidad con una búsqueda, con una necesidad por encontrar el origen de esta otra situación, pero no tenían en sus manos el cómo hallar este inicio, ni supieron dejarse guiar; por lo tanto, extraños a un ambiente, optaron por la imaginación que luchaba por no dejarse desbordar ante lo que tenían frente a sí.

Cuando leemos las crónicas de estos primeros acercamientos vemos que el único recurso a manos era la imaginación y la fantasía (Cristancho, 2004, p. 164).

Hubo la necesidad de enfrentarse a una nueva realidad al momento de La Conquista que agrietó la existencia de lo ya conocido hasta entonces y había que integrar a ese nuevo mundo. La memoria y la historia relatada de esos momentos contenían una combinación de imaginación y realidad que empezaba a cimentar nuestra historia nacional.

De aquí surge una preocupación por comprender la manera en que es concebida la realidad a partir de lo que es transmitido a los alumnos en las escuelas, de acuerdo a lo cual la interpretación y reinterpretación más que los propios hechos es la que condiciona lo que se considera verdadero. Así también aparece la contrariedad de saber si los hechos pueden ser conocidos por sí mismos o es necesario identificarlos por medio de un relato o de su descripción. 
La teoría de "encuadre" o Framing, de Gregory Bateson (1972), expone que hay diferentes maneras de acceder a una misma realidad y darle una gran variedad de significados. Propone seleccionar y enfatizar ciertos aspectos de la realidad, redefiniéndolos, interpretándolos y contextualizándolos para darle determinada dirección a la verdad y mostrar diferentes enfoques adecuados para un sector seleccionado, que en este caso son los niños, quienes a partir de la propuesta tendrían un conocimiento histórico de forma adecuada para ellos. Por lo que se puede entender que de acuerdo con la condición y posición en que se encuentre el observante así será la interpretación que dará a los hechos. Es una manera diferente de entender la realidad a partir de una multiplicidad de puntos de vista y de formulación de realidades. Es atender ciertos aspectos y obviar otros dentro de un mismo episodio. Un mismo acontecimiento, como la Segunda Guerra Mundial, interpretado desde el lado alemán es completamente diferente si es analizado desde el punto de vista inglés. La teoría de Framing es un proceso en el que las personas perciben la realidad desde distintos ángulos y esta puede ser interpretada desde múltiples facetas y no por ello deja de ser verídica, aunque sí es una reconstrucción subjetiva de cierto evento. Ninguno de los casos intenta manipular la realidad sino exponer una alternativa de diferentes formas de percibir un mismo evento, como una pieza más de un enorme rompecabezas. Es una opción de enfocarse en un tema determinado por una gran realidad. Durante mucho tiempo se ha tratado de proteger a los niños del mundo de los adultos exponiéndoles una verdad dosificada que les altera su mirada de la realidad, limitando su conocimiento a lo que consideran apto para ellos, pero hay que valorar qué tan dañina puede ser la verdad objetiva, sin alternativas o, en su contraparte, el exceso de fantasía.

Sin embargo, es importante considerar que el contenido de las historias y sucesos deben de adecuarse a las edades e intereses del sector al que está enfocado y, sobre todo, en el caso de niños y jóvenes, con la etapa que están viviendo, porque de esa forma se tendrá una adecuada interpretación y apropiación de la lectura que realicen. Graciela Montes lo afirma de la siguiente manera:

El realismo mentiroso y el sueñismo eran dos actitudes perfectamente complementarias: alternativamente se "protegía" al niño de las fantasías, $[\ldots]$ alejándolo del mundo de los adultos. La prueba de la delicada ambigüedad con que los adultos pretenden dosificar realidad y fantasía en el brebaje que les preparan a los niños radica en el hecho de qué tan "peligrosa" resulta la fantasía desatada como la realidad sin recortes ni maquillaje (Montes, 2001, p. 23).

Aquí vendría la pregunta: ¿cuál es la realidad? Cuya respuesta depende del enfoque desde donde se observen y se analicen los sucesos. Silvana Vignole explica que: "La verdad misma es entonces una creación humana, que surge para salvaguardar la existencia y garantizar cierta seguridad a un animal inteligente que está empeñado en conservar la vida" (Vignole, 2009, p. 57).

En cambio, Gilles Deleuze lo transmite de la siguiente forma: "Cuando se nos habla de la verdad 'a secas', de lo verdadero tal como es en sí, para sí o incluso para nosotros, debemos preguntar qué fuerzas se ocultan en el pensamiento de esta verdad, o sea, cuál es su sentido y cuál es su valor" (Deleuze, 1971, p. 15). Ya que, el punto de vista del autor, su bagaje y sus 
vivencias intervienen en su propia interpretación. Al momento que un acontecimiento es interpretado por alguien, se muestra parte de la visión y las experiencias de vida que su creador ha tenido dentro del relato debido a que es observado desde su propia perspectiva por más objetivo que se quiera ser.

Lo que lleva a una reflexión sobre la importancia de hacer Historia y su transmisión. Ana Pizarro en su obra La luna, el viento, el año, el día muestra su inquietud hacia este tema de la siguiente manera:

¿Qué es escribir una historia? [...] ¿Quiénes escriben la historia? [...] cada uno de los que escriben está realizando una selección de los datos que ha encontrado, de los acontecimientos que observa, está llevando al escribirlos su propia reflexión; pone así de relieve lo que le parece más importante, calla aquello que le parece poco relevante para su perspectiva. Los problemas que plantean las fichas [...] te van mostrando que la relatividad de la información es bastante grande. La historia, finalmente, no es una [...] La historia que recibimos está de alguna manera siempre escrita desde una posición de poder. El que escribe lo hace porque puede hacerlo. Lo hace desde alguna forma de autorización que se enmarca en ese ámbito. Hay también formas que toman su espacio en terrenos otros, alternativos, marginales [...] Escribir la historia exige leer también otros textos: [...] la arquitectura, la alimentación, la agricultura, la minería, el dato presente y el dato silenciado por la palabra que logró enunciarse. La historia va apareciendo entonces como un texto múltiple (Pizarro, 1993, pp. 66-69).

La Historia al ser escrita desde diferentes perspectivas, abre un abanico de posibilidades de conocimiento, pero es deber del lector constatar desde qué posición es escrito nuestro pasado, pues como lo afirma Pizarro (1993), en muchas ocasiones es escrita desde los mandos de poder, desde las personas que tienen el control del saber histórico de una nación y por ello es importante ahondar en nuestro conocimiento para lograr discernir desde cuál perspectiva proviene. Sebastian Gago lo describe de la siguiente manera: "Los códigos culturales expresan, en medida significativa, la visión del mundo de los distintos grupos que dentro de la sociedad tienen más o menos poder, y que intentan que determinados sectores de la sociedad tomen sus visiones del mundo como referencia" (Gago, 2012, p. 88). Aunque afirma que al orientar a la sociedad hacia ese tipo de enfoques pueden alterar el sentido originario.

En contraste con la Historia oficial se encuentra la Historia popular que plantea una visión diferente de la Historia al esbozar el pasado desde la mirada de las minorías, los olvidados, los oprimidos. Esta historia se encuentra íntimamente relacionada con la microhistoria al evocar a los grupos regionales de nuestro pasado, encontrando la relación entre lo local y lo nacional, vislumbrando que a partir del conocimiento de las distintas regiones es posible comprender mejor la realidad nacional. Se logra acumulando las diferentes experiencias en los pueblos, en los distintos sectores de su vida. Son monografías regionales que permiten comprender las relaciones sociales. Como explica Juan Pedro Viqueira en su artículo "Todo es microhistoria”, “... nos permiten comprender cómo las personas interpretan su momento histórico y cómo, a través de esa interpretación, responden a los pro- 
blemas que se les plantean" (Viqueira, 2008, p. s/r). Se trata de historia basada en personas de carne y hueso, no en aspectos abstractos. A pesar de que los acontecimientos suponen ser elementos objetivos, se rigen por la interpretación subjetiva de los testigos que los explican de acuerdo a lo que ellos consideran que fue esa realidad y en lo que puede llegar a convertirse después. "Los hechos pasados se transforman en un presente que nos interpola y que nos exige una respuesta a través del prisma de un futuro posible, deseado y temido" (Viqueira, 2008, p. s/r).

Para que sea completa la historia de una nación es necesario tomar en cuenta la gran variedad de historias locales y regionales y construirse a partir de ellas. No obstante, la manera de estructurar la historia nacional depende de las múltiples instituciones que rigen el país, que no siempre están de acuerdo y no necesariamente se ocupan de estos aspectos debido a que deben de seguir ciertos criterios e intereses establecidos por las autoridades gobernantes y a las tendencias políticas que manejan.

Lo ideal es crear, según Viqueira:

... una historia nacional que se proponga partir de las vivencias de las personas que la hacen y la padecen, tiene que concederle una atención privilegiada a los intermediarios culturales que enlazan lo local con las redes regionales, nacionales e incluso mundiales (Viqueira, 2008, p. s/r).

Lo óptimo sería explicar la Historia desde la perspectiva de todos los representantes de la sociedad, narrándolo de una forma accesible y amena, apta para el público de todas las edades, explicando en primera instancia su entorno inmediato y a partir de ello dibujar el paisaje nacional. Todos los grupos sociales son primordiales en una nación y conjuntando las historias de cada uno se logra un mayor entendimiento de nuestro pasado.

Al considerar que a los niños hay que alejarlos de los escándalos y los conflictos históricos se puede caer en lo que Montes llama "historia deshistorizada":

El ingreso de la realidad histórica al mundo infantil resulta siempre escandaloso. Para hacerse potable, la realidad debe desrealizarse cuidadosamente, despojándola de todo conflicto. Los libros escolares han sido un modelo de ese mecanismo: héroes, villanos, relaciones sociales emblemáticas y fiestas patrias, la historia deshistorizada (Montes, 2001, pp. 23-24).

Graciela Montes (2001) en Realidad o fantasía o cómo se construye el corral de la infancia aclara que al utilizar el binomio realidad/fantasía para el conocimiento del pasado el adulto mantiene en control la educación de los niños, pero reconoce que poco a poco ha ido cambiando esta tendencia. Ya nadie cree que los chicos vivan en un mundo de ensoñaciones, comprenden que son testigos y actores sensibles de la realidad (Montes, 2001, pp. 24-27).

La enseñanza de la Historia se debe orientar hacia el aprendizaje de conceptos y de la formación del pensamiento. Su intención es proveer al alumno de las herramientas de análisis, comprensión e interpretación sobre el conocimiento histórico para poder reflexionar, juzgar, representar y contextualizar su pasado, diferenciándolo del presente y lograr 
elaborar una conciencia histórica y un pensamiento crítico-creativo, que identifica a los alumnos con su propia historia y su entorno (Almazán, 2015, p. s/r).

De manera que la enseñanza de la historia ha de ser un camino provocador, promotor de la reflexión, de la apertura de sentidos para la percepción de la realidad, vista no como una situación acabada, sino, antes bien, como una síntesis histórica producida por la acción transformadora de los hombres (González y Vera, 2007, p. 38).

Se debe buscar una historia donde los integrantes de la sociedad sean los protagonistas de ella y se logre integrar a aquellas disciplinas que puedan enriquecer su conocimiento. Es una nueva manera de repensarla y de eliminar la serie de datos duros que poco dicen y menos se recuerdan. La intención es verla como una historia viva que nos represente (González y Vera, 2007, p. 38). La nueva generación está interesada por conocer más de su bagaje cultural, pero desde un punto de vista más amplio e incluyente, por lo que es importante acceder a ella desde nuestro presente, cubriendo su necesidad de conocimiento. El interés está enfocado en saber más de la gente común, en personas con las que nos podamos identificar, con defectos y virtudes. Ver la realidad desde otra perspectiva, ya no sólo la de los vencedores, sino también la de aquellos que forman una parte importante de nuestra nación y no se les había prestado la mínima atención. Es momento de desmantelar las veladuras que cubren la diversidad social y mostrarlo con orgullo.

Hay muchas maneras de narrar una misma historia y de narrar la propia Historia. Lo importante es entender que se deben buscar formas alternas de transmisiones más convenientes a las necesidades de los niños de la actualidad.

La narración histórica no oficial además de dar voz a las historias de los integrantes del pueblo, permite que los niños adquieran capacidades para la representación histórica (Almazán, 2015, p. s/r), en donde de acuerdo con Elvia Montes de Oca-Nava:

El profesor debe ser hábil y estar bien informado para hacer vivir la historia y la literatura a sus alumnos; no sólo estudiarlas, sino poner en juego una serie de posibilidades y facultades que ellos y el docente poseen y que están relacionadas con sus habilidades sensitivas, afectivas, emocionales, imaginativas, memorísticas, reflexivas, analíticas, creativas y críticas, permitiéndoles elaborar juicios sólidos y defendibles, y convertir a la literatura y a la historia en campo de búsqueda y de exploración (Montes de Oca-Nava, 2014, p. 59).

Al crear un ambiente de lectura y debate de los conceptos se amplían los horizontes de comprensión individual y colectiva, además de sembrar el cuestionamiento y fomentar la revisión y comparación de eventos. De esta manera, se permite desarrollar en los alumnos nuevas formas de pensamiento y de “... valorar, discriminar, reelaborar, apropiarse de la experiencia vivida en la lectura de la obra; buscar y construir preguntas y respuestas propias; así como comprender el presente para así enfrentarlo de la mejor manera posible" (Montes de Oca-Nava, 2014, p. 60). 
Provocar el cuestionamiento y la discusión de los alumnos sobre la enseñanza de la Historia les abre un universo de conocimiento que absorben más fácilmente al momento de ir resolviendo sus dudas. "El trabajo es provocar el descubrimiento de la realidad, explicitarla, problematizándola orillando a la búsqueda" (González y Vera, 2007, p. 38). Fomentar en los niños un trabajo de investigación y exploración del conocimiento histórico permite una mayor apropiación de los acontecimientos y los conceptos adquiridos.

Es entonces donde la narrativa histórica infantil surge como una excelente alternativa para el aprendizaje de la Historia. Existen diversos géneros narrativos que pueden crear un mayor interés en los niños y jóvenes hacia la Historia. En la actualidad, la gran variedad de estímulos que reciben desde la infancia provoca una necesidad por cambiar las formas tradicionales de enseñanza y la Historia, sin lugar a dudas, es una de las materias que debe hacer uso de las nuevas propuestas.

Los géneros literarios se imponen al escritor siguiendo las exigencias institucionales, siguiendo una organización y estructura específicamente literaria. Sin embargo, éstos pueden cambiar y jugar con los formatos porque los géneros no son estáticos, son entes vivos en la creación, con propuestas innovadoras, provocando un desplazamiento en las categorías. Los géneros son modelos, pero el artista cambia y va cambiando con ellos debido a la necesidad del ser humano por contar y organizar la vida y el cosmos, relatándolos para entender las razones de estar en el mundo, así como para externar los sentimientos, encontrar respuestas y reconocer las pasiones humanas.

De acuerdo con María Estela Eguiarte Sakar la experiencia artística es fundamental para lograr una educación integral, adquiriendo "conciencia de ser y estar en este mundo" (Eguiarte Sakar, 2014, p. 8). La experiencia sensible desarrolla en el niño el pensamiento "imaginativo, creativo, divergente y crítico" (Eguiarte Sakar, 2014, p. 7), como parte de la formación de las personas para lograr un pensamiento propio desde distintas posturas y posibilidades de pensar y comunicar su propia realidad. Lo que les servirá para resolver los problemas de diferente índole que se les presenten, además de ayudar a la construcción de valores y de identificación social (Eguiarte Sakar, 2014, pp. 7-8).

El arte y la cultura impulsados por la creatividad permiten la transformación y la transmisión de valores, así como la cohesión entre individuos, grupos y comunidades, mediante la identificación de ideales, pensamientos y empatías estéticas, emotivas y sensibles (Eguiarte Sakar, 2014, p. 9).

Existen maneras alternativas de enseñar la Historia, desde una perspectiva más accesible e interesante para los niños, y mostrar diferentes facetas de la realidad y la narrativa histórica es una buena opción.

En este sentido, la novela gráfica y el libro álbum, entre otros géneros, como expresión artística, permiten ampliar en los lectores sus habilidades creativas y críticas, así como dar la oportunidad de encontrar nuevas realidades. Al combinar ilustración con textualidad y mostrar eventos de la vida diaria narrados por y para niños, los pequeños pueden absorber mejor el contexto histórico y comprender los momentos trascendentales de la Historia, y así identificarse con los personajes. 
Más que otros géneros, la narrativa histórica refleja la conciencia histórica del tiempo del escritor y, por lo tanto, propone una lectura de la Historia Oficial interpretada desde el presente.

... las relaciones entre historia y ficción son históricas en sí: cambian con el tiempo y con los distintos paradigmas géneros y/o modalidades discursivas dominantes [...] Los discursos de la nación, la literatura y la historia están entrelazados por medio de múltiples conexiones que adquieren características específicas y temporalmente determinadas: la historia usa modelos literarios y una de las principales preocupaciones de la historiografía es la formación de la nación; la nación se concibe en los términos ideológicos e históricos del proyecto liberal y se imagina, sobre todo, a través de la literatura; y la literatura, a su vez, se vuelve tanto histórica (e historicista) como nacional (Unzueta, 1996, p. 13).

Friedrich Nietzsche (2004) vio de otra manera la enseñanza de la Historia: “¡Con tal de que aprendamos siempre mejor a cultivar la historia para servir a la vida!” (Vignole, 2009, p. 27). De acuerdo con su experiencia: "La tarea de la historia es servir de mediadora entre ellos [los tiempos] y así continuamente incitar a promover la creación de lo que es grande" (Vignole, 2009, p. 81). Para él, el conocimiento histórico sólo encuentra sentido si es útil para la vida, por eso va en contra de enfocar la historia únicamente con fines académicos, a pesar de reconocer que la vida del hombre necesita de la Historia para poder comprenderse, pero piensa a su vez que un exceso de ella puede ser dañino porque pierde su fuerza creativa y deja de servirle al hombre para su existencia. Además, despliega tres aspectos por los que el ser humano pertenece a la Historia. En primer lugar, por ser un ser activo y perseguir un objetivo; en segundo lugar, porque salvaguarda y admira sus creaciones; $y$, en tercer lugar, por experimentar sufrimiento y necesidad de liberación (Vignole, 2009, p. 28).

Nietzsche explica que es relevante el saber histórico en los niños y jóvenes, pero de forma activa y en relación al porvenir:

Tenéis bastante para ponderar e inventar al reflexionar sobre la vida del futuro, pero no pidáis a la historia que os indique el cómo y con qué medios. Si, en cambio, penetráis en las vidas de los grandes hombres, de ellas aprenderéis el supremo mandamiento de aspirar a la madurez y escapar de la paralizante educación de la época presente que ve su utilidad en no dejaros madurar para dominar y explotar a los inmaduros (Nietzsche, 2004, p. 104).

Algunas de las tendencias en la reescritura de cuentos infantiles abordan la memoria histórica, que abarca los relatos basados en la historia "oficial", y “... modifican esta historia para convertirla en narraciones con una gran dosis de ficción e intimismo" (Guerrero Guadarrama y Soto van der Plas, 2010, p. 163).

En la posmodernidad se retoma el pasado desde el presente, sin copiarlo, sino desde una relectura crítica “... para establecer una especie de diálogo irónico con el pasado artístico y 
social" (Guerrero Guadarrama, 2010, p. 170). Se resignifica para mostrarlo como parodia posmoderna.

Resulta que no todo es decir algo nuevo sobre la base de un material original. Un buen número de ensayos de gran calidad resultan de cuestionar, modificar, al menos confirmar explicaciones anteriores a partir de nuevas evidencias historiográficas o de la reinterpretación de viejos materiales (Corcuera de Mancera, 2005. p. 9).

... cuando el lector imagina algo que hace sentido en el contexto de esa realidad, es posible descubrir otros significados (Corcuera de Mancera, 2005, p.12).

En los libros para niños existen dos tendencias con respecto a la difusión del pasado:

La mirada diferente a los acontecimientos históricos que contribuye a comprender los sucesos y da paso a una lectura crítica donde los relatos respetan la historia oficial. En el primer caso se "... permite cuestionar la verdad de un relato con tintes mitológicos." Y se desacraliza a los héroes, humanizándolos (Guerrero Guadarrama y Soto van der Plas, 2010, pp. 177-178). Mientras que, en el segundo caso, se mantienen los estándares nacionales y, por lo general, se utiliza el material que provee la Secretaría de Educación Pública, donde se manejan libros de texto de divulgación histórica que no persiguen una búsqueda literaria. A esta clase de literatura se le conoce como instrumental, escolarizada o informativa (Guerrero Guadarrama, 2012, p. 30).

Considero que es importante exponer a los estudiantes a una historia más humana, con héroes que fueron niños, se equivocaron y tuvieron familias. Una historia donde los niños y jóvenes comprendan el porqué de los sucesos y logren una identificación con sus protagonistas. Sin duda este objetivo también se puede lograr por medio de una propuesta literaria que sea interesante para los lectores y al mismo tiempo les brinde conocimiento. La narrativa histórica parte de la necesidad de enseñar o exponer pasajes de la Historia de forma más amena, atractiva y viable al público en general, combinando la narración literaria con la veracidad de los acontecimientos históricos. Su objetivo combina el deseo de divulgar el conocimiento histórico desde diferentes puntos de vista, de acuerdo al autor, seduciendo al lector con el pasado a través de la ficción. Estas visiones van desde su papel moralizante, autorrepresentativo, objetivo, hasta el identitario o redentor, entre otros enfoques.

Se puede decir que la Historia se integró a la Literatura desde los griegos. En la antigua Grecia los relatos estaban conformados por una combinación de realidades y leyendas basadas en las noticias de quienes habían visto y oído los eventos. El ser humano, por naturaleza, tiene la necesidad de relatar su paso a través del tiempo y ha encontrado en la narrativa una gran herramienta para hacerlo. La Historia es vislumbrada, imaginada y expresada por medio de la Literatura. Sin embargo, al narrar las historias es importante dar cuenta y comprender en qué dirección está escrita la obra y con qué intención, pues ello permite cerciorarse que se trata de una narrativa histórica y no de una historia novelada. La narrativa histórica para niños, al igual que toda la literatura infantil, generalmente es creada por adultos, limitado a lo que "supuestamente" es comprensible de acuerdo con sus capacidades interpretativas y de lo que conviene a sus intereses y a su educación, re- 
flejando los modelos culturales que el adulto desea transmitir a las nuevas generaciones. Es a través de la imaginación, los recuerdos o ideales de los mayores que se elaboran las obras dedicadas a los pequeños. Richard Flynn explica que la tendencia de pensar la infancia desde un ideal dificulta mostrarla como una vivencia, la cual es vista como una representación que el adulto recuerda y recaptura (Flynn, 1999, p. 105). Existe una predisposición por parte de los adultos a reflejar sus experiencias y volcar sus anhelos hacia la infancia, que muchas veces no coincide con sus propias condiciones, ya que sus vidas y contextos sociales se dieron en diferentes momentos. Es importante hacer notar que el niño capta mediante estas obras imágenes de la realidad, no la realidad en sí, por lo que irá adquiriendo diferentes respuestas a la misma historia de acuerdo con sus necesidades e intereses de esos momentos (Cervera Borrás, 2003, p. s/r). El lector tendrá que adaptar a su presente los relatos leídos y así crear su versión personal de la Historia, tanto como su propia historia (Petit, 2002, p. 35).

Los niños, al tener “... su particular forma de aprehender la realidad” (Munita Jordán y Riquelme Mella, 2009, p. s/r) y debido a la manera en que impacta en ellos la producción de los mensajes, requieren que se les proporcionen herramientas que les ayuden a forjar la realidad, considerando en todo momento al niño como receptor.

Al mostrarles a niños y jóvenes los sucesos importantes a través del tiempo se les está formando en el conocimiento del "Tiempo histórico" donde se les abre un panorama de aspectos sociales que no son medidos por los relojes ni por los calendarios, sino por los propios acontecimientos que provocaron algún cambio en la vida diaria de la sociedad. La enseñanza del tiempo histórico provee a los niños de un pensamiento que les permite comprender, analizar e interpretar la Historia de tal manera que logren "... construir su propia representación del pasado ...” (Almazán, 2015, p. s/r), al mismo tiempo que entiendan la distancia que se establece con su presente. Para ello es necesario, de acuerdo con Héctor Almazán los siguientes pasos:

Requiere, en primer lugar, pensar en el tiempo, desplazarse mentalmente en el tiempo y tener conciencia de la temporalidad, para ir construyendo una conciencia histórica que relacione pasado con presente y se dirija al futuro. Requiere, en segundo término, capacidades para la representación histórica, que se manifiesta principalmente a través de la narración histórica y de la explicación causal e intencional. En tercer lugar, imaginación histórica, para contextualizar, desarrollar las capacidades para la empatía y formar el pensamiento crítico-creativo a partir del análisis histórico. Y por último, la interpretación de las fuentes históricas y del conocimiento del proceso de construcción de la ciencia histórica (Almazán, 2015, p. s/r).

La educación histórica tiene como uno de sus principales objetivos la vinculación con el pasado, por lo que, dotar a los niños de una narrativa adecuada para ellos permitirá que al recibir la información de los acontecimientos del pasado la puedan procesar correctamente y les permita relacionarse con sus propias raíces. Los relatos históricos permiten el acceso a mundos alternativos y posibles que se acercan desde diferentes maneras a la realidad. El autor realiza un proceso de creación y el lector de entendimiento. El objetivo del escri- 
tor, en la mayoría de las obras de narrativa histórica infantil, es lograr una conversación con su lector dentro de "un proceso de transformación" para encontrarle una posibilidad de sentido en la búsqueda por la verdad, en una necesidad de concebir al mundo en que viven, que es posible entenderlo gracias a que constantemente es interpretado.

Otro punto a destacar es que en muchas ocasiones al enfocarse en el contenido se pasan por alto los aspectos importantes en una narrativa infantil como: la espontaneidad, la capacidad de asombro, la aproximación al objeto y las imágenes contextualizadas que les dan sentido a las obras. Por lo que hay que recordar en todo momento que el éxito en las obras para niños requiere de originalidad, diferenciación y unificación de visión por el simple hecho de que están hechas ex profeso para ellos y deben combinarse con la popularidad (Nodelman, 1985, pp. 3-7).

Porque debemos "manipular" a los niños -o, para usar una palabra más positiva, educarlos. Si optáramos por respetar su individualidad al negarnos a manipularlos, al negarnos, por lo tanto, a enseñarles nuestros propios valores, tendríamos que renunciar [...] No queremos proclamar la ley: queremos abrir un diálogo (Nodelman, 1985, pp. 10-11).

$\mathrm{Al}$ ampliar en los niños la visión de la realidad se les está creando un carácter crítico que les permitirá discernir, decidir, comparar y recuperar las versiones de nuestra historia, además de adquirir perspicacia, responsabilidad y conciencia de sus decisiones personales, considerando que toda obra revela preguntas sin resolver por el autor.

La obra literaria destinada a los niños debe llevar como una de sus principales características tanto un lenguaje artístico como un tema de interés aceptado por ellos, sin embargo, no siempre coincide con la intención del autor (Cervera Borrás, 1992, pp. 11-13). Es un diálogo entre el receptor infantil y el emisor adulto, con la intención de concientizar y sensibilizar al niño por medio de la creatividad del autor, atendiendo las exigencias y necesidades del receptor (Perriconi, 1983, p. 6).

La literatura infantil permite a los lectores hallar respuesta a sus necesidades, por lo que lo más importante es encontrar la versión adecuada para ellos y buscar adaptaciones y las debidas modificaciones, ya que lo que se pretende es una verdadera comunicación. Juan Cervera Borrás afirma que "la experiencia enseña que con frecuencia los niños entienden el cuento de forma distinta que los adultos. Y ahí está precisamente su encanto y el principio de un camino que han de recorrer solos" (Cervera Borrás, 1992, p. 16). Por ello, las expectativas de los adultos ante la comprensión de los niños no siempre es la correcta, debe incluir la confianza en el niño y el deseo de su desarrollo personal independiente (Cervera Borrás, 1992, p. 23).

Cualquier lector al enfrentarse a un texto presenta dos etapas: el desciframiento de los signos y la conexión con los signos transmitidos (Cervera Borrás, 1990, p. 71).

... si el autor emplea el estilo adecuado y aborda los temas que interesan al niño, éste descubre en el texto que intenta leer, entender y gozar, que el acto comunicativo de la obra literaria, en cierto modo, reconstruye la simultaneidad que él está acostumbrado a vivir. Y esta simultaneidad con dimensiones exis- 
tenciales provoca, a través del lenguaje, una auténtica búsqueda de la realidad que el niño vive unas veces en ámbitos afectivos, y otras, inclusive en ámbitos intelectuales (Cerrillo Borrás, 1990, p. 82).

En la etapa intermedia, entre 7 y 11 años, el niño logra establecer retrocesos y avances en el tiempo. Hay necesidad de dar respuesta a sus inquietudes, por lo que todavía se inclina hacia lo fantástico. Su curiosidad hacia nuevos mundos lo lleva a buscar la vida de otros pueblos y animales. Aún el límite entre lo fantástico y lo real no está bien marcado, pero la literatura fantástica-realista se adapta muy bien a los niños en esta etapa, quienes prefieren las aventuras y lo mágico; la vida salvaje y de animales domésticos; las ficciones legendarias o con un contexto histórico ampliándoles la comprensión de los sucesos; las biografías y las historias heroicas; la exploración de países y culturas desarrollando su mundo de referencia (Cervera Borrás, 1992, p. 26). Juan Cervera Borrás afirma que desde el punto de vista psicológico el hacer uso del imaginario "supone seguridad y fijación en la realidad o evasión de ella", que a pesar de no ser vista siempre de la mejor manera pueden funcionar positivamente desde una orientación creativa y a través de ello transformar la realidad (Cervera Borrás, 1992, p. 32). Se necesita un argumento dinámico que equilibre diálogo y acción y describa de forma rápida y básica el ambiente y los personajes. Debe seguir un ritmo que lleve al lector a la comprensión sin dejarle duda o confusión (Cervera Borrás, 1992, p. 26).

En cualquier tipo de expresión artística, lo primero que se establece entre el receptor y la obra es una especie de diálogo a partir de las vivencias del primero y las características estéticas que le expone la obra. Por lo tanto, cuando, un niño o un adulto se acercan a un texto literario, deben acatar lo que la obra manifiesta, citando a Munita Jordán y Riquelme Mella (2009): “... suspende[r] las reglas propias de la comunicación funcional, y [sumergirse] en la lógica interpretativa que le exige el carácter estético propio de ese texto" (p. $\mathrm{s} / \mathrm{r}$ ). Sin embargo, algunos géneros literarios como expresión artística permiten ampliar en los lectores sus habilidades creativas y críticas, así como dar la oportunidad de encontrar nuevas realidades. Esto es posible gracias a lo que la narración enuncia a partir de reinventar su realidad y cautivar al lector.

Se trata de una literatura capaz de seducirnos, mientras reflexiona sobre el presente y organiza con imaginación las múltiples, infinitas sensaciones que despierta la realidad. Nos encontramos en presencia de una obra de ficción que cumple un papel de extraordinaria vitalidad, porque posibilita la explotación y la conceptualización hipotética y experimental de la vida a través del juego (Janer, 1993, p. s/r).

En la actualidad, los historiadores le dan cada vez más importancia a la narratividad. El historiador une los diferentes fragmentos de información, decide la forma narrativa e interpretativa que quiere emplear y escoge la opción literaria que más le acomode, agregándole su presente y su bagaje personal. Lo primordial es mantener la unidad y la coherencia de la obra. Se llevan los géneros literarios a tal límite que es difícil encasillarlos dentro de uno de los cánones establecidos. Combinan el formato del cómic, la fuerza gráfica, las 
históricas y las memorias -tanto personales como familiares- para crear, de esta manera, una narrativa histórica infantil particular, que, en cada uno de los casos, enriquece la educación de los niños. Sin embargo, para lograr una buena recepción es importante que la transmisión sea adecuada e interesante.

El historiador tiene como precepto "hacer hablar" lo real y, en este intento, lo produce haciendo verosímil lo que escribe, instituyéndose como "la verdadera representación de lo que sucede o de lo que sucedió" (De Certeau, 2007, pp. 7-8). Debe actualizar el pasado para poder crear un vínculo y, de esa manera, reinterpretarlo, hacerlo comprensible para representarlo en nuestro presente. La narración de la Historia puede estar asociada a la búsqueda de intereses creados, a situaciones determinadas de vidas pasadas en nuestro presente. Una interpretación objetiva del pasado produce una verdad con tantas facetas, que le da oportunidad al lector de encontrar una gran variedad de lecturas.

Habrá quien se pregunte, ¿ cómo se le puede explicar a un niño cuál es la realidad y cuál es la ficción dentro de una novela histórica infantil? Pues se logra gracias a un proceso de extrañamiento donde el receptor, en este caso infantil, recibe la ficción de forma distinta a la realidad. El mensaje consigue su objetivo al brindar una mirada asombrosa de lo real, o algo nuevo, ya sea invención o recreación, con lo que el receptor recibe imágenes diferentes a las ya conocidas (Sánchez Corral, 2003, p. 181). Es entonces que esta recepción en el lenguaje literario no busca confundirse con la realidad del mundo exterior, es ficcional. El lector tras entender un significado, lo "desentiende". El lenguaje es diferente al usual, se sale del cauce tradicional, recrea con él una forma verbal de su particular modelo de mecanismo de defensa. El niño tiene la facilidad de evocar por medio de la imaginación mundos inéditos pero coherentes.

$\mathrm{Al}$ enfocar la narrativa histórica a los niños se les da la oportunidad de integrarla a su mundo y ser parte de su desarrollo, de ser: “... un sujeto que construye su historia apoyándose en esos fragmentos de relatos, en esas imágenes, en esas frases escritas por otros, y que extrae de ellas su fuerza" (Petit, 2002, p. 30). "Es ante todo porque les permite descubrirse o construirse, darle forma a su experiencia, elaborar sentido" (Petit, 2002, p. 16). Y de esa manera los niños logran construir su identidad.

La narrativa histórica, independientemente de crear discursos ficcionales, permite mostrar la realidad desde otra perspectiva y no por ello implica una evasión. Al contrario, es otra manera de apreciar un mismo escenario o a nosotros mismos. Es una posibilidad de encontrarnos con nuestra propia cotidianeidad y concebirla a través de las experiencias ajenas. La infancia lo aprovecha mucho mejor debido a que ha tenido mucho menos vivencias que el adulto.

... la experiencia artística le permite al niño una reconstrucción de la realidad, la experiencia literaria le brinda la posibilidad de vincularse con la palabra, la imagen, el sonido, así como disfrutar a través de un juego lúdico del goce de la alteridad, ponerse en el papel del otro, asumir un personaje a través de planos de identificación, disfrutar de la ficción, diferenciándola de la realidad, actitud esta que asume el niño con menos barreras que el adulto (Puerta de Pérez, 2003, p. 118). 
En la recepción de una obra literaria el lector, en este caso el niño, entiende, asimila e inventa para reconstruir lo leído, incluyendo aspectos de percepción, pensamiento e imaginación (Puerta de Pérez, 2003, p. 117).

Además de lo anterior, en la recepción literaria interviene la relación con el mundo exterior, a partir del cual se establece un abanico de posibilidades que permite elaborar significados. De acuerdo con Lev S. Vigotsky (2008), la comunicación, como función primordial del lenguaje, crea un "intercambio social" por medio de la narrativa que, a través de su palabra, ya sea oral o escrita, permita la comunicación y la mediación cultural. Esto da la posibilidad al niño de que por medio de las lecturas pueda expresar sus emociones y sentimientos, identificarse con personajes y comparar vivencias, compartiéndolos con otros (Puerta de Pérez, 2003, pp. 118-119).

Es importante señalar la presencia de nuevas tecnologías en la vida y en la formación de los niños, lo que indiscutiblemente repercute en su vida diaria. Estas nuevas generaciones están experimentando nuevas formas de acceder a la información con diferentes carencias y habilidades de las que nosotros tuvimos durante nuestra infancia, lo que ha provocado una transformación del modelo cultural: "ya que hemos pasado de la supremacía de una cultura alfabética, textual e impresa a la de otra que se construye mediante imágenes audiovisuales" (Cerrillo Torremocha y Senis Fernández, 2005, pp. 23-24). Estas modificaciones perceptuales son indicadores de cambios necesarios, desde el tipo de lenguaje usado hasta su capacidad de razonamiento.

La novela histórica es un espacio narrativo donde converge la significación que construye identidades y memorias colectivas. Es un recinto simbólico en donde descansa la construcción y deconstrucción de un ser histórico. Buscar la reflexión, el mirarse a sí mismo, la confrontación con el otro a través del juego del espejo, esperando verse a través de la imagen del otro reflejado allá y aquí en lo que se es (Cristancho Albornoz, 2004, p. 155).

Buscar nuevas alternativas para la transmisión de la Historia por medio del lenguaje literario permite ampliar el potencial educativo al mostrar el contenido desde una perspectiva más actual y más atractiva para los niños. La narrativa histórica al mostrar diferentes enfoques de la realidad, da cabida al cuestionamiento y a una propia interpretación y reconstrucción. Además de otorgar conocimiento, es esencial proporcionar la posibilidad de discernir, valorar e identificar lo leído, para poder aprovecharlo en el propio presente. La Historia como asignatura en los colegios de educación básica se ha caracterizado por contener una gran cantidad de nombres y fechas que saturan y atosigan a los alumnos, sin tomar en cuenta que ellos ya pueden tener esos datos al alcance de un "click".

Nuestra niñez requiere una educación más interactiva y actualizada, por lo que sería conveniente escuchar sus necesidades e inquietudes, que se puede hacer desde las aulas o en sus propios hogares. Los libros de texto deben ser atractivos e interesantes para que los alumnos se acerquen más a ellos. Cada vez se observa una mayor aproximación a los medios electrónicos, lo que permite un proceso más interactivo, sin embargo, considero que todavía hay un camino muy largo por emprender para lograr que los niños se emocionen al conocer su propia historia nacional. Carretero lo expresa así: “... no hay duda de que 
la enseñanza de historia en muchas escuelas de todo el mundo tiene que continuar en el camino de los cambios y reajustes en pos de los nuevas perspectivas y resultados" (Carretero, 2013, p. 20).

La narrativa histórica puede ser una buena herramienta para esta labor, proporcionando diferentes visiones e imágenes sobre nuestra historia. La utilización de recursos electrónicos, así como de narrativas alternativas enriquece el conocimiento y crea mayor curiosidad en los niños y jóvenes, logrando así un mayor contacto de ellos con su propio pasado. Cada vez es más imperativo mantenerse al día en la tecnología y proporcionar los elementos necesarios a cada generación.

Si desde que son pequeños, las escuelas provocan en los niños un interés e inquietud por saber más de su historia, al mismo tiempo que se les da un sentido de vida y pertenencia, se está garantizando una conciencia social e histórica que les permitirá de adultos luchar por sus valores, además de darles la oportunidad de encontrar variadas facetas y distintos puntos de vista para así lograr entender su historia desde múltiples perspectivas. Cada época le va agregando su propio presente, por lo que es una historia en construcción, que se irá complementando a través del tiempo. Hoy más que nunca debemos insistir en una educación inclusiva e interdisciplinaria, que al mismo tiempo sea atractiva y permita el cuestionamiento, porque es la única manera de darle un valor a nuestra historia.

\section{Referencias bibliográficas}

Almazán, F. (2015). “Cómo enseñar historia en el siglo XXI” [Presentación en Power Point]. Disponible en: https://es.slideshare.net/HectorAlmazanFabian/como-ensear-historiaen-el-siglo-xxi

Bateson, G. (1972). Steps to an ecology of mind: Collected essays in anthropology, psychology, evolution and epistemology. San Francisco, CA: Chandler.

Carretero, M.; Castorina, J. A.; Sarti, M.; Van Alphen, F., y Barreiro, A. (2013). "La Construcción del conocimiento histórico". Propuesta Educativa, 1 (39), 13-23. Disponible en: http://www.propuestaeducativa.flacso.org.ar/archivos/articulos/35.pdf

Cerrillo Torremocha, P. C., y Senis Fernández, J. (2005). "Nuevos tiempos, ¿nuevos lectores?". Revista OCNOS, (1), 19-33. Disponible en: http://www.revista.uclm.es/index.php/ ocnos/article/view/166

Cervera Borrás, J. (2003). "La literatura infantil en la construcción de la conciencia del niño”. Monteolivete, (9-10), 21-36. Disponible en: http://www.cervantesvirtual.com/ obra-visor/la-literatura-infantil-en-la-construccion-de-la-conciencia-del-nino--0/html/ ffbceca0-82b1-11df-acc7-002185ce6064_5.html

Cervera Borrás, J. (1990). "Problemas de la literatura escrita para niños". En P. C. Cerrillo y J. García Padrino (coords). Literatura infantil (pp. 67-84). España: Ediciones de la Universidad de Castilla-La Mancha.

Cervera Borrás, J. (1992). Teoría de la literatura infantil. España: Ediciones mensajero, Universidad de Deusto. 
Cristancho Albornoz, S. (2004). "La narratividad y su significación simbólica en la novela histórica”. Contexto: Revista Anual de Estudios Literarios, 8 (10), 155-168. Disponible en: https://dialnet.unirioja.es/servlet/articulo?codigo $=1252815$

Corcuera de Mancera, S. (2005). Voces y silencios en la historia. Siglos XIX y XX. México: Fondo de Cultura Económica.

De Certeau, M. (2007). Historia y Psicoanálisis. México: UIA/Instituto Tecnológico y de Estudios Superiores de Occidente.

Deleuze, G. (1971). Nietzsche y la filosofía. Barcelona: Anagrama.

Eguiarte Sakar, M. E. (2014). "Arte y educación: sensibilidad, creatividad y cognición en la diversidad cultural". Nierika. Revista de estudios de arte, (6), 7-11. Disponible en: http:// revistas.ibero.mx/arte/uploads/volumenes/6/pdf/NIERIKA-NUM6.pdf

Eloy Martínez, T. (1996). “Mito, historia, ficción: idas y vueltas”. En A. Mora, W. Irish y S. Schmidt. (Comps). Visiones cortazarianas. Historia, politica y literatura hacia el fin del milenio (pp. 109-132). México: Aguilar.

Flynn, R. (1999). “'Infant sight': Romanticism, Childhood, and Postmodern Poetry”. En J. H. Mcgavra. (ed). Literature and the Child: Romantic Continuations, Postmodern Contestations, (pp. 105-129). United States: University of Iowa Press.

Gago, S. (2012). "Los estudios de recepción, una necesidad del campo de la historieta argentina”. En A. M. Peppino Barale (coord.). Narrativa gráfica. Los entresijos de la historieta (pp. 81-104). México: Universidad Autónoma Metropolitana.

González, E. y Vera, G. (2007). "La enseñanza de la historia en una realidad dinámica. Reflexiones urgentes”. Navegando, (2), 35-40.

Guerrero Guadarrama, L. (2012). Posmodernidad en la literatura infantil y juvenil. México: UIA.

Guerrero Guadarrama, L. y Soto van der Plas, C. (2010). "Reescrituras, subversiones paródicas e intertextualidades desde la posmodernidad”. En B. A. Roig Rechou, I. Soto López y M. N. Rodríguez (Coords). Reescrituras Do Conto Popular (2000-2009) (pp. 163-187). Vigo: Edicións Xerais de Galicia.

Janer, M. (1993) “La provocación lúdica del libro infantil”. Boletín. Asociación Española de Amigos del Libro Infantil y Juvenil, (24), 7-25. Disponible en: http://www.cervantesvirtual. com/obra-visor/boletin-asociacion-espanola-de-amigos-del-libro-infantil-y-juvenil--6/ html/p0000001.htm

Mata, C. (1955). "Retrospectiva sobre la evolución de la novela histórica". En K. Spang, I. Arellano y C. Mata. (Eds). La novela histórica. Teoría y comentarios (pp. 13-63). España: Universidad de Navarra.

Montes, G. (2001). Realidad o fantasía o cómo se construye el corral de la infancia. México: Fondo de Cultura Económica.

Montes de Oca-Nava, E. (2014). "La novela histórica como apoyo para la enseñanza de la Historia de México”. La Colmena, (84), 57-67.

Munita Jordán, F. y Riquelme Mella, E. (2009). "La arquitectura de la ficción y el lector infantil: conjeturas sobre el proceso de articulación en la comprensión literaria”. Estudios pedagógicos, 35 (2), 261-268. Disponible en: http://www.scielo.cl/scielo.php?script=sci_ar ttext\&pid=S0718-07052009000200015, consultado el 16 de mayo de 2014 . 
Nietzsche, F. (2004). Sobre la utilidad y prejuicio de la historia para la vida. (D. Garzón, traductor). España: Biblioteca Edaf 249.

Nodelman P. (1985). Touchstones: without special title. United States: Children Literature Association.

Perriconi, G. (1983). El libro infantil: cuatro propuestas críticas. Buenos Aires: El Ateneo.

Petit, M. (2002). “Pero ¿y québuscan nuestros niños en sus libros?”. México: Consejo Nacional para la Cultura y las Artes.

Pizarro, A. (1993). La luna, el viento, el año, el día. Santiago de Chile: Fondo de Cultura Económica.

Puerta de Pérez, M. (2003). "La literatura y la estética de la recepción (un estudio exploratorio en niños)”. Contexto, 7 (9), 109-120. Disponible en: http://www.saber.ula.ve/ bitstream/handle/123456789/18880/maen_puerta.pdf;jsessionid=0246C074415A57BB 870C336DEA2CB71C? sequence $=1$

Sánchez Corral, L. (2003). "El texto y la competencia literaria infantil y juvenil”. En P. Cerrillo y S. Yubero (eds.). La formación de mediadores para la promoción de la lectura (pp. 171-182). España: CEPLI.

Unzueta, F. (1996). La imaginación histórica y el romance nacional en Hispanoamérica. Lima-Berkeley: Latinoamericana.

Vignole, S. (2009). "Alternativas a la Historia en el pensamiento de Nietzsche". Instantes y Azares. Escrituras nietzscheanas, (6-7), 51-66.

Vigotsky, Lev S. (2008). La imaginación y el arte en la infancia. México: Editorial Coyoacán. Viqueira, J. P. (2008). “Todo es microhistoria”. Letras Libres, (113), 48-57. Disponible en: https://www.letraslibres.com/mexico/todo-es-microhistoria

\begin{abstract}
The new generations require and demand new ways of learning. It is necessary to rethink and update the knowledge that is imparted in the classroom. The teaching of history must be reformulated. From children's historical narrative, the new technologies applied to the Framing Theory, to a process of defamiliarization, to creative aesthetic resources and to the literary reception in its interaction with the external environment, may all open a wide range of possibilities and foster a space for reflection, understanding and identification with the past.
\end{abstract}

Keywords: Historical narrative - Children's literature - History - Teaching - Framing.

Resumo: As novas gerações necessitam e exigem novos métodos dê aprendizagem. É necessário repensar e atualizar os conhecimentos que impartimos. O ensino da História nas salas de aula precisa ser reformulado. As novas tecnologias aplicadas à teoria de Framing (encuadrar) e a um processo de "estranhamento", a recursos estéticos, creativos e a recepção literária em sua interação com o meio exterior, através da narrativa histórica infantil, são uma alternativa para abrir um grande leque de possibilidades e fomentar um espaço de reflexão, compreensão e identificação com o passado. 
Palavras chave: Narrativa histórica - Narrativa infantil - História - Aprendizajem - Framing.

[Las traducciones de los abstracts fueron supervisadas por el autor de cada artículo] 